\title{
The modern mechanism of cultural globalization
}

\author{
Jie Kang \\ Shaanxi Normal University, Xi'an, Shaanxi, 710119, China
}

Keywords: Globalization, Cultural globalization, Modernity.

\begin{abstract}
Cultural globalization is closely related to the concept of modernity. From the perspective of modernity, cultural globalization is inevitable. Globalization includes both economic and cultural meanings, while cultural globalization is the common expression of various local cultures. Its deep appeal is rooted in the requirements of modernity and its expansion. Modernity, relying on three dynamic mechanisms, has achieved global expansion and formed a picture of cultural globalization. The emergence of modernity and its expansion into the world fit the development track of human society and eventually developed into the common life demand of human society. The modernity mechanism of cultural globalization determines that cultural globalization will gradually surpass the dominant position of western culture and develop together with the excellent traditional cultural in local culture for the expression of global common life style.
\end{abstract}

\section{Introduction}

Discussion of cultural globalization will inevitably mention the concept of "modernity". As one of the important topics concerned by the academic circle at the end of the 20th century, scholars have expounded on this to different degrees. For example, Tomlinson believed that "in the discussion of the relationship between globalization and culture, the modernity of globalization could at least be preserved as a theoretical background". Different from Tomlinson's theoretical background of taking modernity as cultural globalization, Anthony Giddens, a representative of western modernity theory, believed that globalization was one of the fundamental consequences of modernity, and "modernity was experiencing the process of globalization internally". Giddens made a point here: globalization was actually the globalization of modernity. Whether regarding modernity as one of the theoretical backgrounds of the study of cultural globalization or regarding globalization as the fundamental consequence of modernity, in the 21st century today, the close relationship between modernity and cultural globalization cannot be ignored, and it is helpful for us to understand cultural globalization more deeply.

Scholars often use modern words to describe the profound changes in western society since the enlightenment, among which Giddens' views had a great impact among contemporary academia. Giddens made a systematic analysis in "The consequence of modernity" and proposed the dimension of globalization on this basis. This idea was accepted by some scholars, while criticized by some others. For example, Tomlinson believes that "the systematic exposition of Giddens is mainly in the field of social analysis, not in the field of cultural analysis". In fact, although Giddens expounded modernity and globalization from the perspective of system, Giddens' discussion has rich cultural implications at the same time. Giddens believes that "modernity refers to the social life or organization model" and "modernity, in an unprecedented way, enables us to abandon the track of all types of social order and form its life attitude". Culture is the expression of a specific way of survival and life, and a stable value concept and spiritual pursuit formed in practice and experience of daily life. Certain groups always show a certain value tendency in their daily behaviors, which reflects a certain cultural pattern. From the perspective of the course of human history, modernity has separated western society from the theological rule of traditional society and gradually formed a series of values and spiritual pursuit with rationalism as the core in modern society, including liberalism and individualism. In modern society, these values and spiritual pursuits have become the dominant values guiding people's daily life and behaviors. As Giddens says, "In terms of connotation, 
modernity is changing the most familiar and personal areas of our daily lives." Therefore, the concept of modernity of Giddens does not only remain at the level of social analysis as criticized by Tomlinson, nor is it merely cultural modernity in the narrow sense of aesthetics. Giddens' modernity is a brand-new way of survival and life compared with traditional society, and is a new cultural expression.

\section{Characteristics of modernity}

As a kind of cultural expression, modernity was originally a unique phenomenon in western society, which affected the social practice and life style of western society, and opened up the period of modernity in western society. That is to say, the initial development of modernity only represents a kind of local cultural appeal, but this kind of cultural appeal different from traditional society has certain advantages compared with other local cultures and is naturally extended outwards, which is the biggest characteristic of modernity. This characteristic enables the value appeal of modernity to break through the local constraints and transform into a global and universal value pursuit with the help of the new time and place by all means, so that the cultural appeal of modernity can be spread globally and thus presenting a picture of cultural globalization. If the generation and dissemination of modernity in western society at the beginning was its starting and developing stage, then the cultural appeal of modernity in global development is a new historical stage of modernity development. In this new stage, the development of modernity has become an expression of the global common life style, which is first reflected in the economic field, then permeated into various fields like ideological, scientific, cultural, political, etc., and is changing human life and the face of earth day by day. Human society presents the situation of mutual dependence and development. Although this is only a trend of phenomena, it points out the most important qualitative determinations of globalization. Whether people believe it or not, understand it or not, agree with it or not, globalization will move forward in accordance with its own development logic, and will not develop rapidly in accordance with anyone's subjective will.

\section{Giddens' analysis of the mechanism of modernity}

According to Giddens' analysis, modernity relies on three dynamic mechanisms: the separation of time and space, the development of disembedding mechanism and the reflective application of knowledge, completing the plan from local to global, realizing global expansion, and finally forming the picture of cultural globalization.

Giddens believed that the difference between modern and traditional societies lied in the relationship between time and space. In pre-modern societies, space and place were always the same, for example, people in traditional societies could only depend on the place where the event happened to determine the time of its occurrence. However, under the condition of modernity, time and space are separated due to the invention and use of mechanical clock, and the relationship of distance also influences and constructs the nature of the place just like the present objects. It is also because of the separation of time and space that the symbolic signs and expert systems included in disembedding mechanism can be formed and developed. These two main disembedding mechanisms enable "social actions to be 'extracted' from the context of localization and to reorganize social relations across the broad time-space distance". The emergence of money, one of the most important symbolic signs described by Giddens, has shifted human economic activities from a narrow space to a broader sphere. On the other hand, the reflection of modernity based on the separation of time-space, namely the reflective application of knowledge, has different characteristics from pre-modern civilization. "The production of systematic knowledge about social life becomes an inherent part of the reproduction of the social system, thus making social life free from the traditional constant constraint." In this sense,

Giddens put forward the connection between globalization and modernity, "modernity is experiencing the process of globalization internally, which is obvious in most of the basic characteristics of modern systems, especially in the aspect of disembedding and reflection of these 
institutions". The characteristics of modernity in the aspect of disembedding and reflection show that modernity is inherently expansive. Through the reconstruction of time and space, modernity can be extended and expanded globally. On this basis, globalization is actually the process of the constant extension and expansion of modernity, while cultural globalization is the result of the extension and expansion of cultural appeal of modernity.

\section{Modernity is a kind of local cultural appeal which is totally different from traditional society}

Modernity, as an expression of the way of survival and life, was formed and developed in the process of struggling with the traditional thoughts of medieval Europe, and was a local cultural appeal totally different from traditional society. While analyzing the origin of capitalism, Max Weber demonstrated the culture peculiar to western society -- rationality. Weber considered that western modern capitalism was based on rational organization, people used rational methods to solve social problems in social life. With the development of western society, western society has developed many values on the basis of rationality, such as the individualism of realizing individual value through individual efforts, the liberalism of striving for individual freedom and equality and utilitarianism, and developed them into the dominant value of western society. Under the guidance of these values, western society has developed various disembedding mechanisms and penetrated them into all aspects of social life, thus transforming people's daily life into a rational pattern. For example, with the emergence of various expert systems, modern people are constantly connected with various disembedding social relations in their daily life. We are in contact with the technical knowledge of various expert systems, rather than the experts who invent various expert systems. For another example, the formation and dissemination of various cultural products and the rise of mass culture are not only the expression of the meaning of human survival, but also the expression of instrumental rationality to some extent. However, modernity at this time was only a local planning, and it was a local cultural expression formed and developed in the process of European society struggling against various traditional thoughts and striving for its own liberation and development. The expansive nature of modernity would not limit the cultural expression to the local, and the time-space separation gives the broader space for the development of modernity to expand globally. The cultural appeal of modernity, with the help of various modern media technologies, has achieved global expansion.

The generation of modernity and its global expansion fit the development track of human society. As the western countries took the lead in completing modernization and produced modernity, the western countries showed strong productivity level and cultural achievements in the process of moving to the modern society. The backward countries took the modernization level of western countries as their development goal, which also included the rational life attitude and life style represented by modernity. "What distinguishes western civilization from other civilizations is not the way it develops, but the uniqueness of its values and institutions. The most prominent features include Christianity, pluralism, individualism and the rule of law, which enable the west to create modernity, expand globally and become the envy of other societies”. The modernity originated in western society shows its strong attraction, and the concepts of rationality, freedom and equality are also indispensable to enter modern society. With the help of various disembedding mechanisms, these values constantly expand their scope of influence through the construction of new time-space, thus gradually evolving into a kind of global planning.

At present, cultural globalization has become an irreversible development trend, and the cultural picture of globalization presents the situation of the coexistence of mono-culture and diversified culture.

Cultural globalization with highly modernity is actually the expression of the common life style of global people, and it is in this sense that cultural globalization indicates a single cultural phenomenon. Just like today, human society has appeared some common life issues, such as ecological destruction, collapse of economic growth mechanism , growth of totalitarian , nuclear war and large-scale war. In the practice of globalization, human society generally realizes that the values of rationality, freedom, equality and fairness are indispensable conditions for modern social communicating. 
In all of these ways, we can all argue that globalization has created a single cultural pattern to some extent, while this single cultural pattern is generally dominated by western culture.

However, in the process of cultural communication, non-western culture does not blindly accept western culture unilaterally, but constantly displays its own cultural charm, simultaneously affects western culture in the opposite way, and intensifies the deep recognition of local culture to its own cultural system. As modernity represents the advanced social system and social life style and has strong attraction, the backward countries will consciously or passively absorb these appeals. At the same time, local culture also hopes that its cultural tradition can be accepted by the global cultural system. Therefore, local culture will also beyond the limitation of local time-space, and take the initiative to integrate the cultural traditions in local culture that meet the requirements of modern culture into the discourse system cultural globalization, and become a part of the global culture recognized by different cultural patterns.

\section{Conclusion}

In short, the cultural appeal of modernity generates the scene of cultural globalization through various disembedding mechanisms and reflective application of knowledge. The modernity nature of cultural globalization determines that western culture cannot always dominate, nor does it mean the disappearance of local culture. With the development of society, the cultural appeal of modernity will gradually surpass the dominant position of western culture and develop together with the excellent cultural tradition in local culture into the expression of global common life style. The history of China and the history of the world shows that culture is never a single one, but a multiple compound. In the context of globalization, every local culture should make its own culture respond to it, instead of building a wall and maintaining its own purity, which is historically impossible and even less possible now. The correct solution should be to solve the problems of cultural confidence, cultural integration, cultural inheritance and cultural dependence, so as to make the local culture active in the integrity and interconnection of cultural globalization.

\section{Acknowledgements}

This research was financially supported by the general project (Grant NO. 17SZYB15) of the fundamental research fund project of the central universities of Shaanxi normal university.

\section{References}

[1] John Tomlinson. Globalization and culture. Trans. Yingjian Guo. Nanjing: Nanjing university press, 2002, P99, P84.

[2] Anthony Giddens, Consequences of Modernity, Trans.He Tian, Nanjing: Yilin press, 2011, P152, p1-4, P143, P56, P46.

[3] Max Weber, The Protestant Ethic and The Spirit of Capitalism, Trans. Guoxun Su , et al., Beijing: Social science academic press, 2010, P287. 